\title{
Internet of Things (IoT) : Charity Automation
}

\author{
Maher Omar Alshammari \\ College of Computer Sciences \& IT \\ King Faisal University, \\ Saudi Arabia
}

\author{
Abdulmohsen A. Almulhem \\ College of Computer Sciences \& IT \\ King Faisal University, \\ Saudi Arabia
}

\author{
Noor Zaman \\ College of Computer Sciences \& IT \\ King Faisal University, \\ Saudi Arabia
}

\begin{abstract}
People are living in cities and villages based on their profession and their earnings. Those who have better earnings can live their live nicely. However, those who do not have good earnings are facing difficulties to survive their lives even for their basic necessities such as food and clothes. Government and limited charity organizations are trying to help them. In the Kingdom of Saudi Arabia few charity organizations placed few donation boxes around the city to collect donations on donor's ease, but it has become hard for them to monitor them regularly, which affect the donation condition. Involving the Internet of Technology (IoT) will give the donors' comfort and fast way to communicate with the charity, which will make the donation process efficient, easier and in well-organized as well. This paper presents a smart solution which is based on advanced technologies namely; Smart Charity (SC) that will help charity organizations, donators and needy people by involving IoT. SC working mechanism based on two folds, 1)Web-Based Application and 2)Android-based smart Application that will enable donors to donate through their mobiles anywhere and anytime, as well they can suggest the best time for them so the charity organization's representative can visit and collect the desired donations. SC will enable the charity organization to know the location of donors and needy people through GPS as well. In addition, SC introduces Smart Donation Box (SDB) concept by involving IoT, which will have the capability to communicate with charity organizations about its current status such as quarterly, half or fully filled.
\end{abstract}

Keywords-Smart city; Smart Charity; Internet of Things (IoT)

\section{INTRODUCTION}

Willing to help needy people is a great nobleness. It is not hard to help other people, especially if the help process is simple and easy for you, and for others it could mean everything for them. That is donating which is an active way of helping others. In return, Smart Charity (SC) project produced a system, which aims for helping needy people (people who need money, clothes and food). One of the main goals for SC is to replace old fashion of paper work, and involve the Internet of Things (IoT) to help make better donation boxes that called Smart Donation Box (SDB). With a wide range of technologies available across our daily life, we have found an appropriate way by producing smart system that is the combination of an Android smart phone application and a Web-based application. Donors are able to use the application to enter their information and specify the location with the help of GPS coordinates. On the other hand, the web-based application enables charity organizations to manage the process of donation. Finally, the Smart Donation Boxes are able to notify/communicate with the charity organization timely to ensure that the donations are not wasted.

\section{BACKGROUND}

In Saudi Arabia, people are willing to help and donate for needy people. Based on official statistics from the Alber Charity Organization in Al-Ahsa at 2015 that the number of physical donations is $12,787,060$ SR [1]. In fact, the number is larger, but huge amounts of expected donations are wasted because there is no efficient way to collect and distribute them.

Currently there are several applications which exist to help in the donation process, such that Saudi Food Bank "Eta'am", "Makkah charity", " NemahKeep " and "Alber Charity".

According to our investigation and visiting to these organizations, the donators must come to the charity offices to make the donation, while with Eta'am charity you have to contact them and send an earlier request before you have any ceremony. As well with the other application NemahKeep, the donator must call the responsible for collecting the donations by cell phone and tell them the address. What about in the large cities it will be difficult for the charity to know the exact location. In big cities, it will be hard for charity organizations to keep track of all donation boxes and collect them timely. Dar_Alkhair recently launch new smart donation box. However, the main function of the new box is change light color from green to the red at the top of the box to intimate the donors will know that the box is filled.

Smart Charity project will expand the existing applications by providing the efficient search about the donator's location through (GPS) and the convenient time for collecting the donation. In addition, SC sends a notification message to the needy people if any new donation arrives for them, and what is the best time that the charity may send the donation to them. SC are stores the information of donators and needy people privately and securely in a database.

In the same time, SC will address big issue "Ignored donation boxes", that none of the existing applications takes good care of it. SC will provide an easy fast efficient solution for the charity donation boxes, by providing smart hardware device depend on IoT [2] that will forward a message to the charity organization whenever the donation box is filled.

\section{LITERATURE REVIEW}

This section provides a detailed literature review specifically about the existing applications for the donation, which are trying to increase and activate the donation process, and make it easier.

There are numbers of existing systems and charities organization that are increasingly trying to activate the 
donation process, to make it more suitable and use the technology to reduce the effort of the donator. This section will explore some charities donation process and recent works in this field one by one.

Eta'am charity organization [3] is a charity organization that mainly focuses on helping needy people by collecting extra healthy food from different parties and delivers it to needy people after packing. Their process of donation is that the donator should contact the charity and tell them about the type of the food and best suitable time and date to collect the food. Eta'am uses a website that shows the latest news, updates about the organization, and allows the donors to donate through their website as well. Eta'am also, uses a mobile application to do the same job as the website. However, following are the limitations of this system.

- Only accepting food donations from big ceremony minimum invited are 70 guests.

- The donator cannot create account, each time they have to fill up the form repeatedly and send it to the charity.

- There is no interaction between the donors and the charity.

- The needy people cannot register them self in easy way in order to receive donations.

- The registered needy people by the charity cannot update their location automatically in case if their location is changed.

Makkah charity organization [4] is a charity organization that helps the needy people by receiving donations at their offices on specific scheduled time or by bank transferring through their accounts. They have several programs one of them is helping needy people by providing them the necessary living hood. However, following are the limitations of this system.

- They use the website for showing their latest programs and their bank account details only.

- Donators have to visit the charity organization in order to donate physical donation like 'Clothes'.

- There is no interaction between the donors and the charity.

- The needy people cannot register them self in easy way in order to receive donations.

- The registered needy people by the charity cannot update their location automatically in case if their location is changed.

- The needy people cannot set a priority of their need.

NemahKeep [5] is helping by collecting unneeded healthy food from the ceremonies and hotel restaurants then organize it again to deliver it for Makkah visitors and needy people. Their process of donation is that the donator should contact the responsible of NemahKeep by phone and give them the location, the best time and date to collect the food. NemahKeep charity uses a Twitter account to show the latest news and other statics about the donations, as well they have a YouTube channel for showing some videos that motivate people to donate. NemahKeep uses the cellphone for communication with the donator. However, following are the limitations of this system.

- They do not use the technology in efficient way to help in donation process.

- Donators have to call responsible of NemahKeep in order to donate.

- There is no easy way that gives the donors motivation to donate.

- The needy people cannot register them self in easy way in order to receive donations.

- The registered needy people by the charity cannot update their location automatically in case if their location is changed.

Alber charity organization \& Dar_ Alkhair charity organization [1] are one of the biggest charity organizations in Saudi Arabia that collect money from the government, companies, rich people and donators. As well, the charity collects the physical donations through donation boxes around the city. The charity has a website and a mobile application for showing the latest news about the charity and their work. However, following are the limitations of this system.

- They do not use the technology in efficient way.

- Donators have to visit the charity organization in order to donate physical donation like 'Clothes'.

- The charity ignores the donation boxes for long time.

- The cost of checking the donation boxes is high and makes a lot of effort to the charity employee.

- There is no mechanism to check the status of donation boxes.

- The needy people cannot set a priority of their need.

Rahman, Akter, Hossain, Basak and Ahmed [5] they proposed Smart Blood Query, which use smart mobile application in order to enable donator to use the app they have to register their necessary information including blood type and the current location, the app enable the blood seekers to see the nearest blood donators, and contact with them through SMS. In case if the blood donator's response with 'NO' a new search will be initiated to find the nearest blood banks and SMS will send to the recipient, provide them with some information, the blood donors have option to accept the donation request by reply to the SMS 'YES' or deny it by reply 'NO'. The App ass well, enables donator to update their information include location and availability. However, following are the limitations of this system.

- The system does not use GPS future in order to update the donor's location automatically.

- There is no confidentiality of the donor's information.

- The system is for blood donation only. 
AlDossari, AlMubarak, AlBukhowa, and AlSaif [7] they proposed smart system namely: Life Doners, which is an application that try to address the issues related to blood donation in the emergency. Life Doners are trying to link the patients, donors and the hospital in one system, the proposed system have an android app which will be used by the donator to specify their information along with the suitable time for them, so in case if there is emergency situation required the donors blood the hospital can search for the nearest suitable donor. As well, the proposed system using a website for the hospital to manage the blood donation process effectively. However, following are the limitation of this system.

- The proposed system is for blood donation only.

Khan and Qureshi [8] the proposed system is a web-based 'blood management system' for Pakistanis citizens. In the proposed system the blood donator registers them self in the system and fill up the necessary information along with the contact number and blood type, the patients can contact blood donors through the system or by the phone in order to achieve the required blood donation. Overall, the proposed system is useful for the admin and patients to know the contact number of the blood donators. However, following are the limitation of this system.

- The proposed system is website only.

- Donors cannot specify their available time to donate blood.

- Does not use GPS features in order to know the location.

- There is no confidentiality of the donor's information.

- The proposed system is for blood donation only.

AlHashim, Al-Madani, Al-Amri, Al-Ghamdi, Bashamakh, and Aljojo [9] they proposed a Blood Management System that allows the willing donors to donate, and help the registered hospitals in the system to keep a record of the donor's data in case if they need to communicate with them. The proposed system easily enable the hospitals to register in the system and enter what type of blood they in need. The target of this system is to make it easier for donors to know which hospitals are in need for their blood type in case if they want to donate. However, following are the limitation of this system.

- The proposed system use website only.

- The proposed system is for blood donation only.

- Does not use GPS features in order to know the hospital location.

\section{SC SYSTEM ANALYSIS}

This section explains how the Smart Charity system will work.

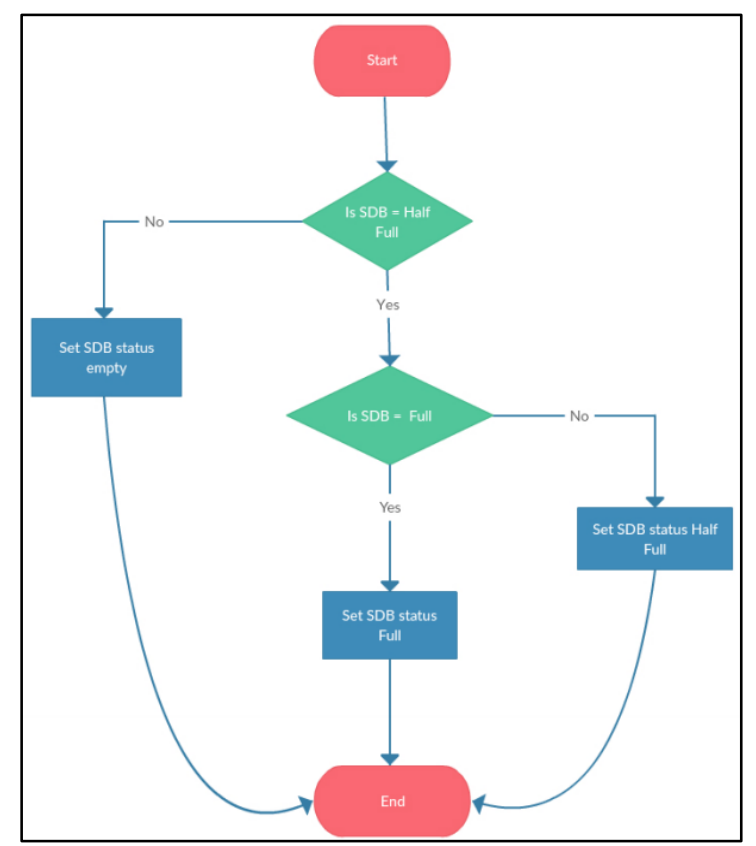

Fig. 1. Flow chart of smart donation box

Figure 1 shows the flow chart that explains the flow of the Smart Charity Donation box device, at the beginning the Arduino Uno start the connection with the charity organization website server and check the status of the box if the low-level sensor is cut and the high level are cut also that means the donation box is full, in this case, the system will update the status of the donation box to full. Otherwise, if only the lowlevel sensor is cut the donation box status will update it halffull and connection with the server close.

Step 1: Start Connection

Step 2: Check the low level sensor "half full"

Step 3: If low level sensor are cut

Step 4: check the low level sensor "full"

Step 5: If low level sensor are cut

Display donation box are full

Else

Display donation box are Half-full

Else

Display donation box are empty

Step 6: Close Connection

Fig. 2. Smart Donation Box algorithm

Figure 2 shows the donation box algorithm, in the beginning, the Arduino start a connection with the charity server, after that the sensor scan and deduct the objects inside the donation box. In case if the items reach to a certain level the Arduino will notify the charity. 


\section{SC SYSTEM GUI DESIGN}

This section shows the system GUI design which includes the smart box donation SBD prototype

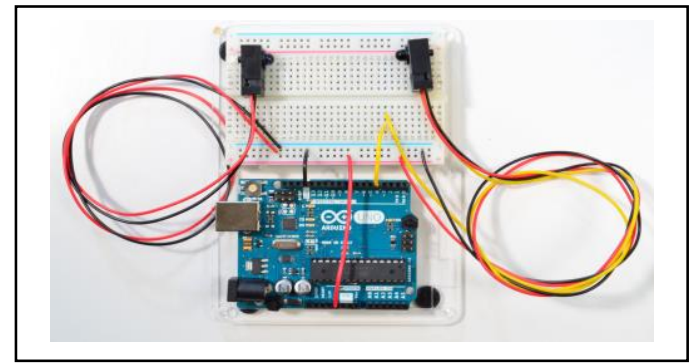

Fig. 3. Main component of the donation box

Figure 3 shows the main component of the Smart Donation Box Device, which is Arduino Uno board used as a microcontroller. Infrared IR Sensor used to determine the status of the donation box. Arduino Wi-Fi shield used for communications with the charity organization server.

Figures 4 shows the registration page for the donators as well for the needy people, needy people will have to check the checkbox and enter more information after the user(donator or needy people) complete the information and click on register button they will see a notification message in case of the registration completed or failed

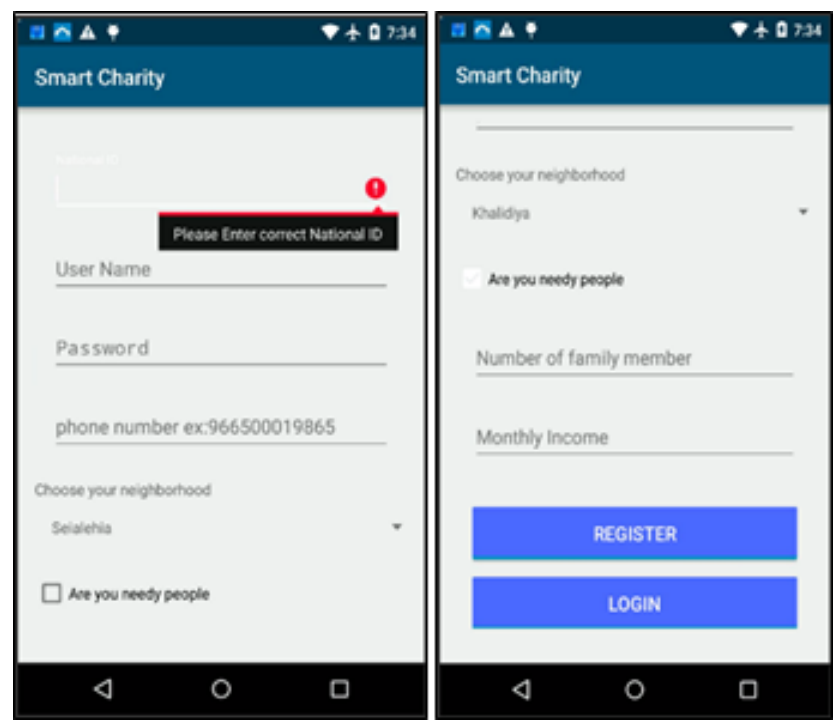

Fig. 4. Android app registration page

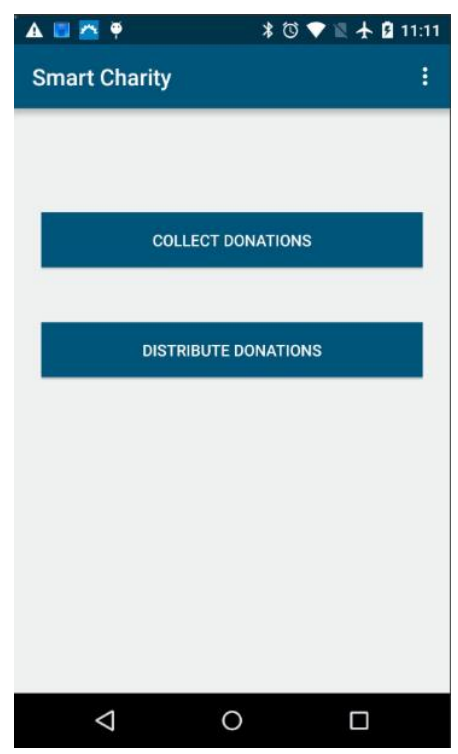

Fig. 5. Android app donator's page

Figure 5 shows the employee page, there is two buttons: 1collect donations where the employee can see a list of the donors with their information as shown in Figure 6. In addition, Button 2- Distribute donations where the employee can see a list of the needy people with their information. In the same page.

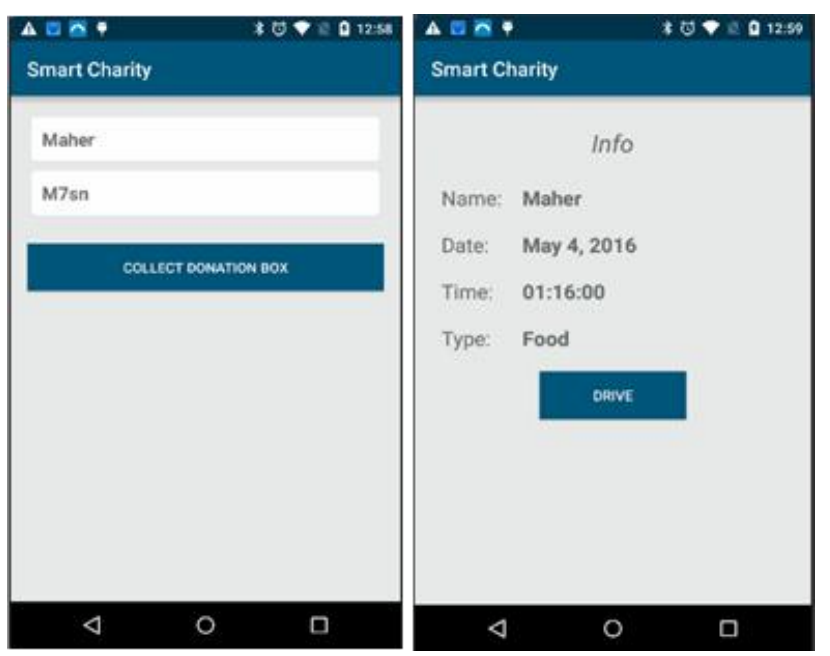

Fig. 6. Android app donor list with their information 


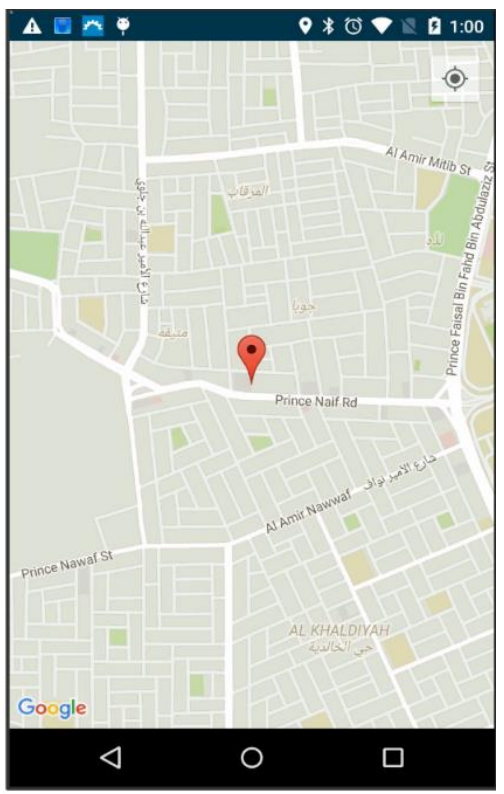

Fig. 7. Android app map page

Figure 7 show the map page where the employee can see the donor's location/needy people's location. After the employee click Collect/Distribute button he will see the donor/needy person information as shown in the previous Figure, and when the employee clicks on Drive button the map page will open where the employee can easily see and drive to the donor/needy person. In the same time, the map page used to see the donation box location in order to collect the donations.

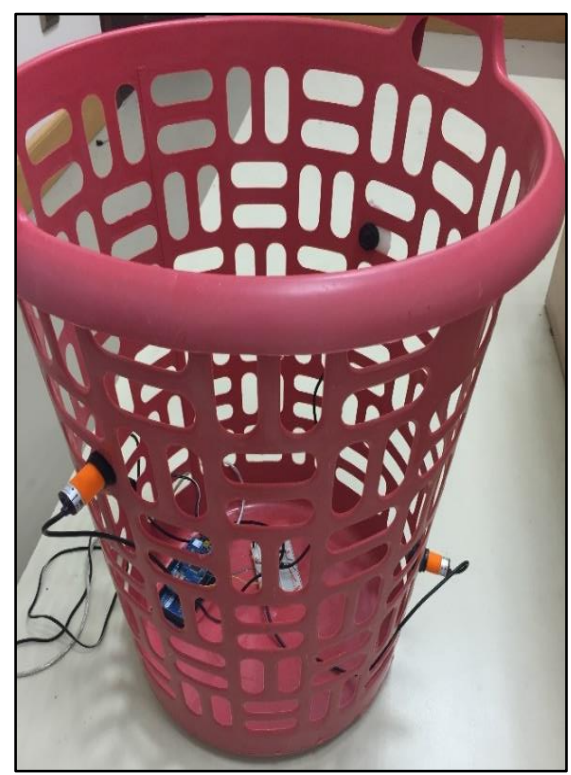

Fig. 8. Smart donation box prototype

Figure 8 shows the prototype of the Smart Donation Box (SDB) which all the component of the system is connected.

\section{CONCLUSION}

The main goal of the Smart Charity (SC) system is to help the society in a modernized way using new era technologies to make donations and charity operations more efficient. SC introduced smart solution for the charity organizations and donation boxes, mostly placed around the city in the Kingdom of Saudi Arabia to turn them into Smart Donation Boxes (SDB) by using IoT, which will enable the existing donation boxes to notify to the charity organizations, when the collected donations reached to certain levels. In addition, SC helps the donors to donate with ease and comfortable way. SC also provides help to the needy people by forwarding them several notifications linked to the charity without feeling need to visit physically to the charity organizations. This system further can be extended to multiple smart gadgets platforms such as IOS, Windows etc. and can be extended to the rest of the world to enhance the ease and efficiency of charity organizations using IoT.

\section{ACKNOWLEDGMENT}

First of all, we would like to take this chance to express our significant appreciation to College of Computer Science \& Information Technology (CCSIT) King Faisal University (KFU) for the support and environment provided to complete our system and implement it as a pilot project. We also extend our gratitude to Dr. Noor Zaman for his supervision, exemplary guidance, monitoring and constant support.

\section{REFERENCES}

[1] Alber charity organization \& Dar_Alkhair charity organization. Access at 1-Sep-15 Retrieved from http://www.albr.org/ and http://ahsaber.org/?page_id=126104 page: 55

[2] Coetzee, Louis, and Johan Eksteen. "The Internet of Things-promise for the future? An introduction." In IST-Africa Conference Proceedings, 2011, pp. 1-9. IEEE, 2011.

[3] Saudi food bank (2015). Access at 9-Sep-15 Retrieved from http://saudifoodbank.com

[4] Makkah charity (2015). Access at 14-Sep-15 Retrieved from http://www.mc.org.sa/

[5] NemahKeep (2013). Access at 26- Sep -15 Retrieved from http://www.hifz.org/

[6] Muhammad Sajidur Rahman, Khondoker Asif Akter, Shakil Hossain,Anjon Basak, Syed Ishtiaque Ahmed. "Smart Blood Query: A Novel Mobile Phone Based Privacy-aware Blood Donor Recruitment and Management System for Developing Regions".

[7] Fatimah AlDossari, Manal AlMubarak ,Marwa AlBukhowa and Maryam AlSaif, Noor Zaman . "Life Donors: saving lives by using current era smart technologies" Journal of Information \& Communication Technology Vol. 9, No. 2, (2015) 55-76

[8] Abdur Rashid Khan and Muhammad Shuaib Qureshi. "Web-Based Information System for Blood Donation". International Journal of Digital Content Technology and its Applications Vol. 3, No.2 (2009).

[9] Sara A. Hashim, Afnan M. Al-Madani, Shatha M. Al-Amri, Abeer M. Al-Ghamdi, Bayan S. Bashamakh. NahlaAljojo, PhD. "Online Blood Donation Reservation And Management system In Jeddah". Life Science Journal Vol 11, No.8, (2014) 